\title{
Impacts of Deflection Nose on Ballistic Trajectory Control Law
}

\author{
Bo Zhang, ${ }^{1,2}$ Shushan Wang, ${ }^{1}$ Mengyu Cao, ${ }^{3}$ and Yuxin $\mathrm{Xu}^{1}$ \\ ${ }^{1}$ State Key Laboratory of Explosion Science and Technology, Beijing Institute of Technology, Beijing 100081, China \\ ${ }^{2}$ College of Engineering, Bohai University, Liaoning 121013, China \\ ${ }^{3}$ AVIC Keeven, Beijing 100081, China
}

Correspondence should be addressed to Bo Zhang; jzhzhb@sina.com and Yuxin Xu; 10802100@bit.edu.cn

Received 9 January 2014; Accepted 27 January 2014; Published 2 March 2014

Academic Editor: Shen Yin

Copyright (C) 2014 Bo Zhang et al. This is an open access article distributed under the Creative Commons Attribution License, which permits unrestricted use, distribution, and reproduction in any medium, provided the original work is properly cited.

\begin{abstract}
The deflection of projectile nose is aimed at changing the motion of the projectile in flight with the theory of motion control and changing the exterior ballistics so as to change its range and increase its accuracy. The law of external ballistics with the deflectable nose is considered as the basis of the design of a flight control system and an important part in the process of projectile development. Based on the existing rigid external ballistic model, this paper establishes an external ballistic calculation model for deflectable nose projectile and further establishes the solving programs accordingly. Different angle of attack, velocity, coefficients of lift, resistance, and moment under the deflection can be obtained in this paper based on the previous experiments and emulation researches. In the end, the author pointed out the laws on the impaction of external ballistic trajectory by the deflection of nose of the missile.
\end{abstract}

\section{Introduction}

Targets in the modern war are changing constantly. The increasing targets with high mobility, extensive depth, and multiple levels put a higher demand on the renovation of the missile technology. Developing the long distance, high accuracy, and powerful missile is regarded as the ultimate destination for this technology. Human beings are dedicated to developing the lighter and more intelligent missile now and even for quite far future. Research on the creative intelligent control technology has very important significance and practical value, where the external ballistics plays a key role in this modern missile control technology. The bomb integrates sensor with actuator, which was developed based on intelligent material and structure. The sensor detects environment information continuously during flight and passes it to a missile-borne computer; the actuator then deforms the nose or wing of the missile according to the decision made by computer. The local structural deformations give the missile additional aerodynamic force and moment, which result in velocity, direction, and center of mass coordinates changes; the center of mass motion is also affected. The trajectory is controlled by changing the missile's aerodynamic characteristics and ballistic trajectory. Trajectory control can improve the missile's target accuracy and range capability. With the increasing demands of modern war and advancement of scientific technology, the external ballistics has enjoyed rapid development in the past 20 years. The external ballistics is a science of mechanics based on motion stability, vibration theory, and aerodynamics, relying on modern control theory and computer technology. On the other hand, it is closely related to the measurement technology. The external ballistics deals with the flight, especially bullets, gravity bombs, aviation bomb, rocket, missile, and the like. Traditionally, the external ballistics only studies the behavior of the projectile and provides the simple trajectory design and firing tables. Some control methods such as data driven fault tolerant control [1-5], robust control [6-9], and so forth have been applied in this field. Recently, the external ballistics has been widely studied in the research fields like trajectory calculation, flight stability, initial disturbance analysis, dissemination, controllable trajectory, integral optimization design, and experiment technology and parameter identification [10-13]. Experts and professors put forward a number of new projects regarding this subject. 


\section{Rigid-Body Dynamic Modeling for Deflectable Nose Projectile}

2.1. Analysis of External Ballistic Trajectory Features and Basic Assumption. Compared with the external trajectory of normal projectile, projectile with deflectable trajectory has the following features.

(1) In the flight of a normal projectile, the aerodynamic force imposed on it is not controllable, while, for the projectile with deflectable nose, its trajectory is partially controllable because there is a control unit controlling the deflection of nose so that its external trajectory is no longer a free trajectory.

(2) Although the trajectory of deflectable nose is controllable, it is different from the controllable trajectory of other projectiles. The control unit can only control the ballistic trajectory to some degree or within some certain section of trajectory, other than complete control.

We can see that the external trajectory is equipped with the features of both normal projectile trajectory and controllable trajectory.

The equation of trajectory of the deflectable nose projectile is set under the following basic assumptions.

Assumption 1. Standard meteorological condition, calm wind, and no rain.

Assumption 2. No mass eccentricity in the projectile; centroid of the whole projectile is kept in the same point after the nose deflection, and the plane is exactly symmetric.

Assumption 3. Omitting the changes to Coriolis inertial force and gravity acceleration along with the changes in latitude.

Assumption 4. Omitting the changes to earth curvature and gravity acceleration along with the changes in height; gravity acceleration $g \approx 9.8 \mathrm{~m} / \mathrm{s}^{2}$ and its direction are vertical to ground.

Assumption 5. No spinning to the projectile (i.e., to neglect the Magnus force, moment, damping moment, and angular moment in the empennage); the projectile flies within the fore-and-aft plane.

2.2. Force Analysis. According to the aerodynamic simulation, due to the existence of an upward relative angle in the nose and the projectile body, the air around the upper surface and lower surface areas is not equal. Pressure in the lower surface is larger than the upper; thus the nose will suffer from lift force [14].

In the flight of the projectile, regardless of the spinning, in order to measure the effects from each force and join forces, forces and moments are simplified to the centroid of projectile. For convenient for illustrating, is given in Figure 1.

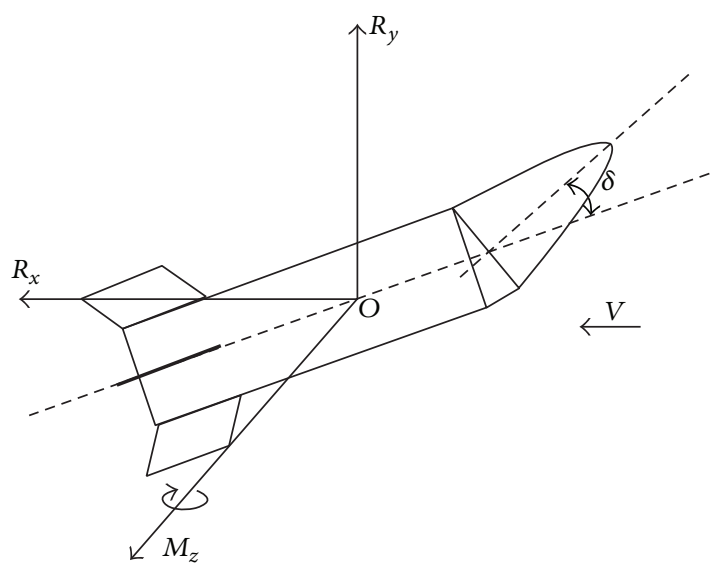

FIGURE 1: Diagram for simplifying aerodynamic forces.

(1) $R_{x}$ is drag and expressed as

$$
R_{x}=\left(\frac{\rho v^{2}}{2}\right) S_{M} C_{x},
$$

where $C_{x}$ is drag coefficient and $S_{M}$ is reference area $\left(\mathrm{m}^{2}\right)$.

(2) $R_{y}$ is lift and expressed as

$$
R_{y}=\left(\frac{\rho v^{2}}{2}\right) S_{M} C_{y},
$$

where $C_{y}$ is lift coefficient.

(3) $M_{z}$ is static moment and expressed as

$$
M_{z}=\left(\frac{\rho v^{2}}{2}\right) S_{M} \operatorname{lm}_{z}
$$

where $M_{z}$ is moment coefficient.

\section{Establishing Rigid-Body Dynamic Modeling}

The motion equation system of the projectile deals with the relationship of forces, moments, and motion parameters. It is composed of equations of dynamics, kinematics, and geometrical relationship. The motion of the projectile in the space is strictly divided into 6 free degrees, where 4 free degrees can indicate its motion laws through the equation, if yaw angle and roll are neglected. By shifting the coordinate systems and referring the motion equation, equations of rigid-body external trajectory can be obtained [14-16].

3.1. The Coordinate System and the Conversion of the Coordinate System. The movement rules of the projectile do not change with the selection of the coordinate system. The coordinate system affects the difficulties of establishing and solving the motion equations or whether it is easy to read the motion equations. References $[15,16]$ are a common coordinate system. 
(1) Ground coordinate system $A x y z$ is used to determine spatial coordinate of the projectile's centroid. The earth can be regarded as holding still; that is, the ground coordinate system can be regarded as the inertial coordinate system.

(2) Body coordinate system $O x_{1} y_{1} z_{1}$ : body coordinate system is a moving coordinate system and body coordinate system $O x_{1} y_{1} z_{1}$ describes the change in the spatial attitude of the projectile, which is relative to the pitch, yaw, and roll motion of the ground coordinate system $A x y z$.

(3) Trajectory coordinate system $O x_{2} y_{2} z_{2}$ is formed by the reference coordinate system's twice rotations. Trajectory coordinate system is fixed with the velocity vector $\bar{V}$ of the bullet centroid, so it is also a moving coordinate system. It is used to establish the kinetics scalar equation of the projectile centroid's movement and study the trajectory's characteristics.

(4) Velocity coordinate system $\mathrm{O}_{3} y_{3} z_{3}$ : velocity coordinate system is also a moving coordinate system, and it is usually used to study the aerodynamic of the projectile.

To establish the projectile motion equation often needs to convert the force or torque in a coordinate system into another coordinate system, so it needs to establish the conversion relationship between the coordinate systems, and these relationships can be obtained by projection or matrix operation.

3.2. Kinematics Equation. Kinematics equation, namely, the relationship equations between the bullet's center of gravity position and the velocity, mainly includes the kinematics equation of the centroid relative to the ground coordinate system and relative centroid of missile body kinematics equation.

3.2.1. Centroid Movement Kinematics Equation. When we study the motion law of missile body, it is generally relative to the ground, therefore, based on the ground coordinate system, the relationship between velocity coordinate system and the ground coordinate system, to get the missile body's centroid kinematics equation:

$$
\begin{aligned}
& \frac{d x}{d t}=V \cos \theta, \\
& \frac{d y}{d t}=V \sin \theta,
\end{aligned}
$$

where $\theta$ is trajectory angle.

3.2.2. Kinematics Equation around the Centroid. Kinematics equation is the relation between the angular displacement and the angular velocity. It can be obtained by taking advantage of the relationship between the missile body coordinate system and the ground coordinate system. Describe the kinematics equation of missile body relative to centroid's rotation 4.2:

$$
\frac{d \vartheta}{d t}=\omega_{z}
$$

where $\vartheta$ is pitch angle and $\omega_{z}$ is angular velocity of the missile relative to ground coordinates.

3.3. Dynamic Equation. Missile body's motion can be decomposed into centroid in vertical plane of translation and the missile body rotation around the centroid. The role on the missile body's force and moment, through the relationship between the two coordinate systems, and projection to ballistic coordinates system according to the Newtonian dynamics relations are as follows.

3.3.1. The Missile Body's Movement around the Centroid Dynamic Equation. Suppose that the missile body's rotational velocity relative to the ground coordinates is $\omega$, and the missile body swings only in the longitudinal plane, so the rotation dynamics equation can be obtained:

$$
\frac{d \omega_{z}}{d t}=\frac{M_{z}}{J_{z}},
$$

where $d \omega_{z} / d t$ is the rotation angle acceleration of missile body, $M_{z}$ is the torque of all the external force in the missile body to centroid, and $J_{z}$ is the missile body equatorial rotation inertia.

\subsubsection{The Missile Body Centroid Dynamic Equation}

$$
\begin{aligned}
& m\left(\frac{d V}{d t}\right)=-R_{X}-m g \sin \theta \\
& m V\left(\frac{d \theta}{d t}\right)=R_{Y}-m g \cos \theta
\end{aligned}
$$

where $d V / d t$ is the tangential acceleration; $V(d \theta / d t)$ is normal acceleration, $\theta$ is trajectory angle, and $\alpha$ is flight attack angle.

There are six equations, $V, \theta, \alpha, \vartheta, x, y, \omega$ seven unknown numbers. And the certain relationship exists between angles $\theta, \alpha$, and $\vartheta$. Therefore, another angle relation needs to be supplied:

$$
\theta=\vartheta-\alpha
$$


TABLE 1: Range of different shooting angles.

\begin{tabular}{lccccc}
\hline Shooting angle $\left(^{\circ}\right)$ & 3 & 10 & 20 & 30 & 50 \\
\hline Ranges $(\mathrm{m}, V=1020 \mathrm{~m} / \mathrm{s})$ & 2,040 & 2,275 & 2,369 & 2,324 & 2,149 \\
Ranges $(\mathrm{m}, V=300 \mathrm{~m} / \mathrm{s})$ & 597 & 1,152 & 1,407 & 1,500 & 1,483 \\
\hline
\end{tabular}

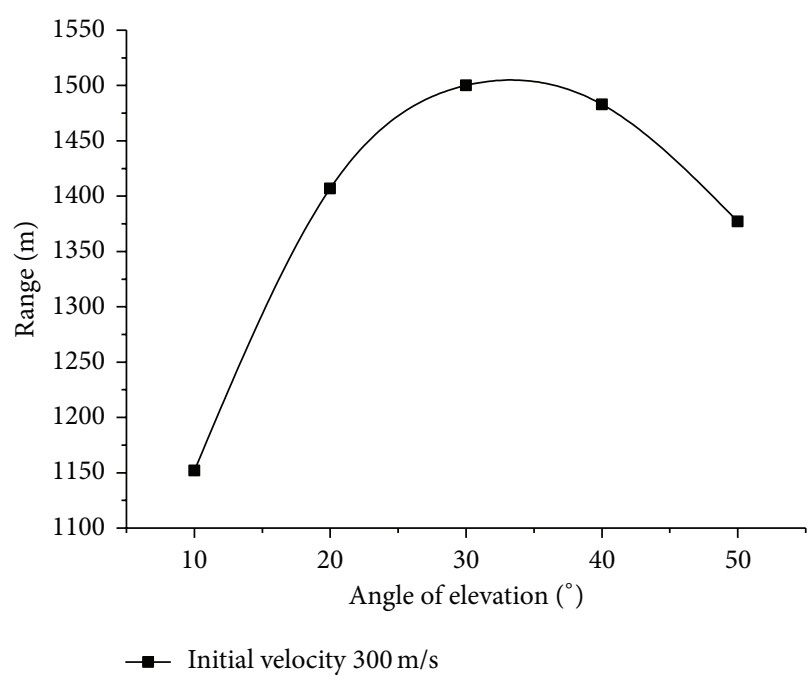

(a) Range changing with different shooting angles in $V=300 \mathrm{~m} / \mathrm{s}$

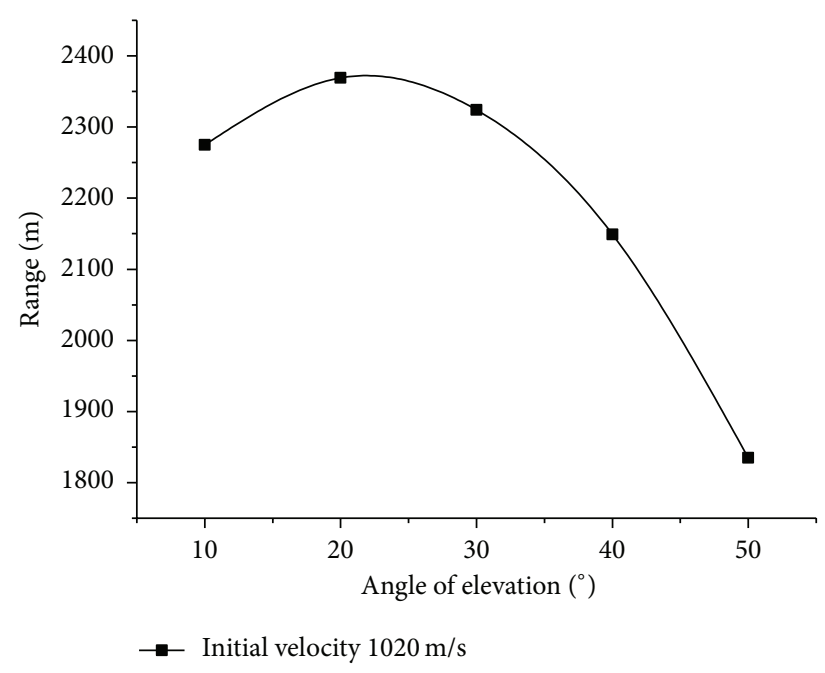

(b) Range changing with different shooting angles in $V=1,020 \mathrm{~m} / \mathrm{s}$

FIgURE 2: Comparison of different ranges with different shooting angles in 2 velocities.

Then (9) can be derived by (4)-(8):

$$
\begin{gathered}
\frac{d V}{d t}=\frac{-R_{X}-m g \sin \theta}{m}, \\
\frac{d \theta}{d t}=\frac{R_{Y}-m g \cos \theta}{m V}, \\
\frac{d \omega_{z}}{d t}=\frac{M_{z}}{J_{z}}, \\
\frac{d x}{d t}=V \cos \theta, \\
\frac{d y}{d t}=V \sin \theta, \\
\frac{d \vartheta}{d t}=\omega_{z}, \\
\theta=\vartheta-\alpha .
\end{gathered}
$$

\section{Simulation Calculations and Results Analysis}

In this paper, trajectory calculation program is designed based on the rigid-body ballistic trajectory modeling to conduct the stimulation calculation for the external trajectory of the deflectable nose projectile. During the ascending pass, the projectile flies in the uncontrollable trajectory, while after the boosting phase, the smart controlling device will be transformed and cause the deflection in nose. A deflection angle relative to the projectile is formed so that the projectile can keep flying along this angle. General analytical solutions of the trajectory equations are always obtained under some assumptions of approximation. Only when we need to take an accurate numerical integration methods for solving the trajectory equations, some numerical integral methods are used such as Euler method, Runge-Kutta method and Adams method. Four-stage Runge-Kutta method is applied in our simulation calculations because of that this methods is a higher accuracy in calculation and easy for designing the program [17-19].

The nose deflection controlling unit is made of piezoceramic [20]. And its deflection scope is controlled within 0 degree to 8 degrees, with initial velocity at $300 \mathrm{~m} / \mathrm{s}$ to $1,020 \mathrm{~m} / \mathrm{s}$. We make the simulation calculation on external ballistic trajectory in different shooting angles and nose deflection angles so as to evaluate different nose deflection angles' impacts on range and further to achieve the maximum correction $[21,22]$.

4.1. Impacts of Shooting Angle on External Ballistic Trajectory. When a projectile is launched at a certain initial velocity, there will be a best angle for maximum range. In order to evaluate the impacts of shooting angle on external trajectory, we calculate and summarize the data of different shooting angles and different shooting range accordingly. We set the initial velocity of the projectile at $1,020 \mathrm{~m} / \mathrm{s}$ and $300 \mathrm{~m} / \mathrm{s}$, respectively; nose deflection angle at $4^{\circ}$; shooting angles at $3^{\circ}$, $10^{\circ}, 20^{\circ}, 30^{\circ}, 40^{\circ}$, and $50^{\circ}$, respectively, as shown in Table 1.

Figure 2 shows initial velocity at $300 \mathrm{~m} / \mathrm{s}$ and $1,020 \mathrm{~m} / \mathrm{s}$ and the comparison of different ranges in different shooting 


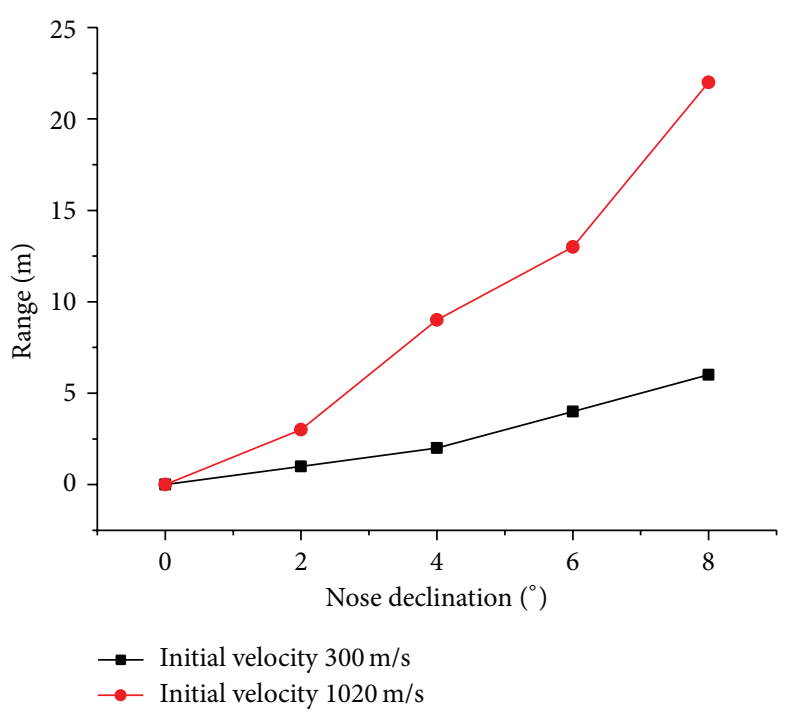

(a) Curve of range changing over nose deflection

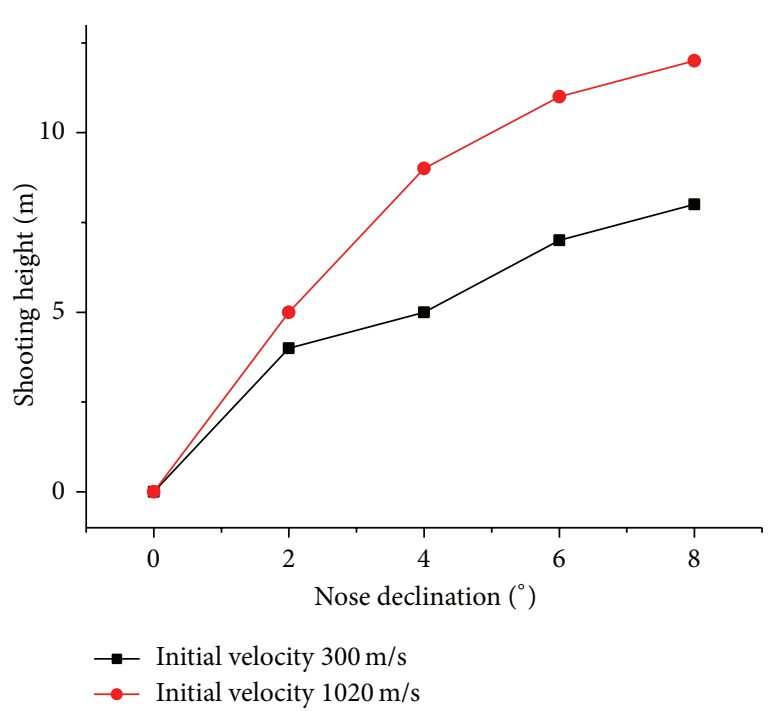

(b) Curve of shooting height changing over nose deflection

FIGURE 3: Curve for corrections of range and shooting height growing over the nose deflection under tow kinds of velocity.

angles and clearly demonstrates that the shooting angle has significant impacts on the external ballistic trajectory. Through the calculation, we work out that velocity at $1,020 \mathrm{~m} / \mathrm{s}$, shooting angle at $22^{\circ}$, the range of the projectile is $2,371 \mathrm{~m}$, which is the longest range. While the shooting angle increases from $3^{\circ}$ to $22^{\circ}$, the range is increased along with the shooting angle. When shooting angle further increases from $22^{\circ}$ to $55^{\circ}$, however, the range is decreased. In the other case, velocity is $300 \mathrm{~m} / \mathrm{s}$ and the best shooting angle is $33^{\circ}$, which makes the longest range to $1507 \mathrm{~m}$. Where the shooting angle increases from $3^{\circ}$ to $33^{\circ}$, the range is increased; while shooting angle increases from $33^{\circ}$ to $50^{\circ}$, the range is decreased. The best shooting angles with two kinds of velocity will be adopted in the later calculation and analysis.

4.2. Impacts of Nose Deflection Angle on External Ballistic Trajectory. In order to explore the impacts of nose deflection on the external ballistic trajectory, we calculate external ballistic trajectory with different nose deflection angle in different initial velocity and best shooting angle. We set the velocity at $1,020 \mathrm{~m} / \mathrm{s}$, shooting angle at $22^{\circ}$, after the boosting stage, and the nose deflection angle at $2^{\circ}, 4^{\circ}, 6^{\circ}$, and $8^{\circ}$ and calculate their external ballistic trajectory. On the other hand, we set the velocity at $300 \mathrm{~m} / \mathrm{s}$, shooting angle at $33^{\circ}$, and the nose deflection angle at $2^{\circ}, 4^{\circ}, 6^{\circ}$, and $8^{\circ}$ and calculate again their external trajectory. Shooting ranges and shooting height changed with the different deflection angles, as shown in Tables 2 and 3.

From the data on its shooting height and range along the time of flight, we can know that the correction value grows over the nose deflection degree. Figure 3 shows the curve of corrections of shooting range and height growing over the nose deflection.

A conclusion can be drawn that initial velocity at $300 \mathrm{~m} / \mathrm{s}$ and nose deflection angle of $8^{\circ}$ can provide the maximum
TABLE 2: Shooting ranges and shooting height with initial velocity $1,020 \mathrm{~m} / \mathrm{s}$ and shooting angle $22^{\circ}$.

\begin{tabular}{|c|c|c|c|c|c|}
\hline Nose deflection $\left({ }^{\circ}\right)$ & 0 & 2 & 4 & 6 & 8 \\
\hline Shooting ranges $(\mathrm{m})$ & 2,366 & 2,369 & 2,375 & 2,379 & 2,388 \\
\hline $\begin{array}{l}\text { Correction values of } \\
\text { shooting ranges }(\mathrm{m})\end{array}$ & 0 & 3 & 9 & 13 & 22 \\
\hline $\begin{array}{l}\text { Correction values of } \\
\text { shooting height }(\mathrm{m})\end{array}$ & 0 & 5 & 9 & 11 & 12 \\
\hline
\end{tabular}

TABLE 3: Shooting ranges and shooting height with initial velocity $300 \mathrm{~m} / \mathrm{s}$ and shooting angle $33^{\circ}$.

\begin{tabular}{|c|c|c|c|c|c|}
\hline Nose deflection $\left({ }^{\circ}\right)$ & 0 & 2 & 4 & 6 & 8 \\
\hline Shooting ranges $(\mathrm{m})$ & 1,498 & 1,499 & 1,500 & 1,502 & 1,504 \\
\hline $\begin{array}{l}\text { Correction values of } \\
\text { shooting ranges }(\mathrm{m})\end{array}$ & 0 & 1 & 2 & 4 & 6 \\
\hline $\begin{array}{l}\text { Correction values of } \\
\text { shooting height }(\mathrm{m})\end{array}$ & 0 & 4 & 5 & 7 & 8 \\
\hline
\end{tabular}

correction value, where maximum correction of shooting range is $6 \mathrm{~m}$ and shooting height is $8 \mathrm{~m}$. While initial velocity at $1,020 \mathrm{~m} / \mathrm{s}$ and nose deflection angle of $8^{\circ}$ can provide the maximum correction value, where maximum correction of shooting range is $22 \mathrm{~m}$ and shooting height is $12 \mathrm{~m}$.

\section{Conclusions}

From the stimulation calculation and analysis on trajectory of deflectable nose projectile, the following conclusions can be obtained.

(1) Because the nose deflection is upward, pressure around the upper surface of the projectile is different from the lower surface. The pressure gap will cause 
the lift force, which makes the projectile rotate around the centroid and finally create a new angle of attack. Under a same working condition, the larger angle for nose deflection, the more changes to the aerodynamic coefficients and the greater correction obtained.

(2) As to the range extension, when the missile body is set at the initial velocity of $1,020 \mathrm{~m} / \mathrm{s}$, its range will be longer than at the velocity of $300 \mathrm{~m} / \mathrm{s}$. When it is set at the deflection angle of $8^{\circ}$ and shooting speed of $1,020 \mathrm{~m} / \mathrm{s}$, the shooting range can be extended with $0.93 \%$; when shooting speed is set at $300 \mathrm{~m} / \mathrm{s}, 0.40 \%$ of range can be extended. And with the increase of angle of attack, shooting range and shooting height present a rising trend. Thus, the conclusion can be obtained that comparatively more obvious effects of nose deflection control to ballistic trajectory at the high speed with large angle of attack conditions can be seen than those at low speed with small angle of attack.

(3) In the future studies, by applying the impacts of angle of pitch on ballistic trajectory in the yaw angle, we can build up the relevant models and programs to make the calculations on two-dimensional trajectory of deflectable nose projectile and external ballistic trajectory.

In conclusion, the deflection in nose can cause the projectile to change its motion in flight. Therefore, it is feasible and effective to control the ballistic trajectory by changing the nose deflection angle.

\section{Conflict of Interests}

The authors declare that there is no conflict of interests regarding the publication of this paper.

\section{References}

[1] S. Yin, S. X. Ding, A. H. A. Sari, and H. Hao, "Data-driven monitoring for stochastic systems and its application on batch process," International Journal of Systems Science, vol. 44, no. 7, pp. 1366-1376, 2013.

[2] S. Yin, S. X. Ding, A. Haghani, H. Hao, and P. Zhang, "A comparison study of basic data-driven fault diagnosis and process monitoring methods on the benchmark Tennessee Eastman process," Journal of Process Control, vol. 22, no. 9, pp. 1567-1581, 2012.

[3] X. Zhao, L. Zhang, P. Shi, and M. Liu, "Stability of switched positive linear systems with average dwell time switching," Automatica, vol. 48, no. 6, pp. 1132-1137, 2012.

[4] X. Zhao, L. Zhang, P. Shi, and H. Karimi, "Novel stability criteria for T-S fuzzy systems," IEEE Transactions on Fuzzy Systems, 2013.

[5] S. Yin, X. Yang, and H. R. Karimi, "Data-driven adaptive observer for fault diagnosis," Mathematical Problems in Engineering, vol. 2012, Article ID 832836, 21 pages, 2012.

[6] X. Zhao, P. Shi, and L. Zhang, "Asynchronously switched control of a class of slowly switched linear systems," Systems \& Control Letters, vol. 61, no. 12, pp. 1151-1156, 2012.
[7] S. Yin, G. Wang, and H. Karimi, "Data-driven design of robust fault detection system for wind turbines," Mechatronics, 2013.

[8] X. Zhao, L. Zhang, P. Shi, and H. Karimi, "Robust control of continuous time systems with state dependent uncertainties and its application to electronic circuits," IEEE Transactions on Industrial Electronics, vol. 61, no. 8, pp. 4161-4170, 2014.

[9] S. Yin, H. Luo, and S. Ding, "Real-time implementation of faulttolerant control systems with performance optimization," IEEE Transactions on Industrial Electronics, vol. 64, no. 5, pp. 24022411, 2014.

[10] W. Zhong-Yuan, "Aerodynamic force and external trajectory optimization design of Armour-Piercing Discard Sabot (APDS)," Acta Aerodynamica Sinica, vol. 11, no. 3, pp. 270-276, 1993.

[11] X. Ming-You, Advanced External Ballistics, Higher Education Press, Beijing, China, 2003.

[12] W. Zhong-Yuan and Z. Wei-Ping, Theory and Method of External Ballistics Design, Science Press, Beijing, China, 2004.

[13] J. Sahu, Time-Accurate Numerial Prediction of Free Flight Aerodynamics of Projectiles, IEEE Computer Society, 2006.

[14] H. Zi-Peng, X. Xiao-Zhaong, and Z. Ying-Yi, External Ballistics, National Defence Industry Press, Beijing, China, 2000.

[15] Q. Xing-Fang, L. Rui-Xiong, and Z. Ya-Nan, Missile Flight Mechanics, Beijing Institute of Technology Press, Beijing, China, 2006.

[16] W. Fei, W. Zhi-Jun, and W. Guo-Dong, "Numerical calculation of extended-range artillery rocket base on intelligent material," Journal of Projectiles Rockets Missiles and Guidance, vol. 20, no. 4, pp. 325-327, 2004.

[17] F. Wang, G.-D. Wu, Z.-J. Wang, and X.-H. Kang, "Numerical calculation of aerodynamic characteristics of shell with attack angle at the shell head," Journal of North China Institute of Technology, vol. 26, no. 3, pp. 177-179, 2005.

[18] W. Fang-Hai, W. Zhi-Jun, and W. Guo-Dong, "A new method of ballistic correction by controlling the nose angle of rocket," Journal of Projectiles Rockets Missiles and Guidance, vol. 26, no. 2, pp. 928-930, 2006.

[19] H. Ji-Chuan, L. Zhan-Chen, and X. Zeng-Hui, "Research of the exterior trajectory correction technology based on piezoelectricity ceramic," Journal of Projectiles, Rockets, Missiles and Guidance, vol. 28, no. 6, pp. 201-204, 2008.

[20] L. Shuai, W. Jin-Zhu, Z. Wei-Jun et al., “Trajectory simulation for guided rocket," Foreign Electronic Measurement Technology, vol. 30, no. 12, pp. 69-71, 2011.

[21] W. Meng-Long, W. Hua, and H. Jing, "Rockets trajectory correction method based on nose cone swinging," Journal of Detection \& Control, vol. 33, no. 4, pp. 23-27, 2011.

[22] Z. Ying-Hun, T. Guo-Hui, and D. Ming-Li, "Research on aerodynamic characteristics and ballistic characteristics of finstabilized rocket at high altitude," Journal of Projectiles, Rockets, Missiles and Guidance, vol. 31, no. 2, pp. 142-144, 2011. 


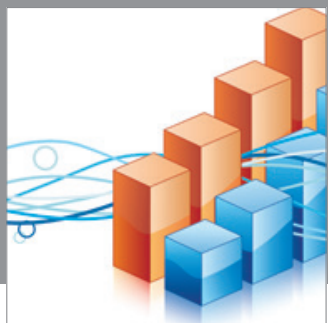

Advances in

Operations Research

mansans

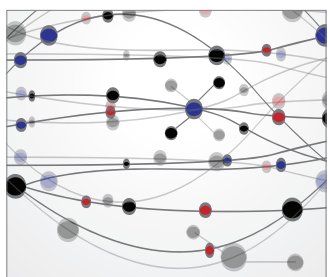

The Scientific World Journal
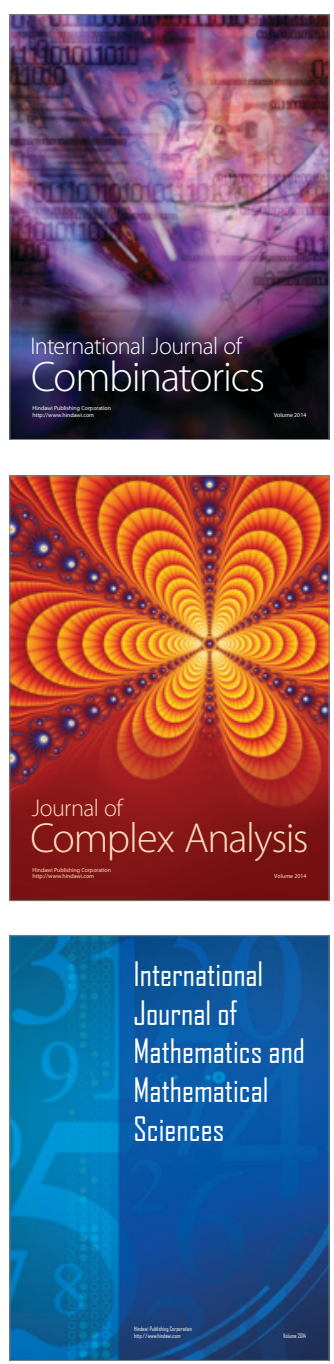
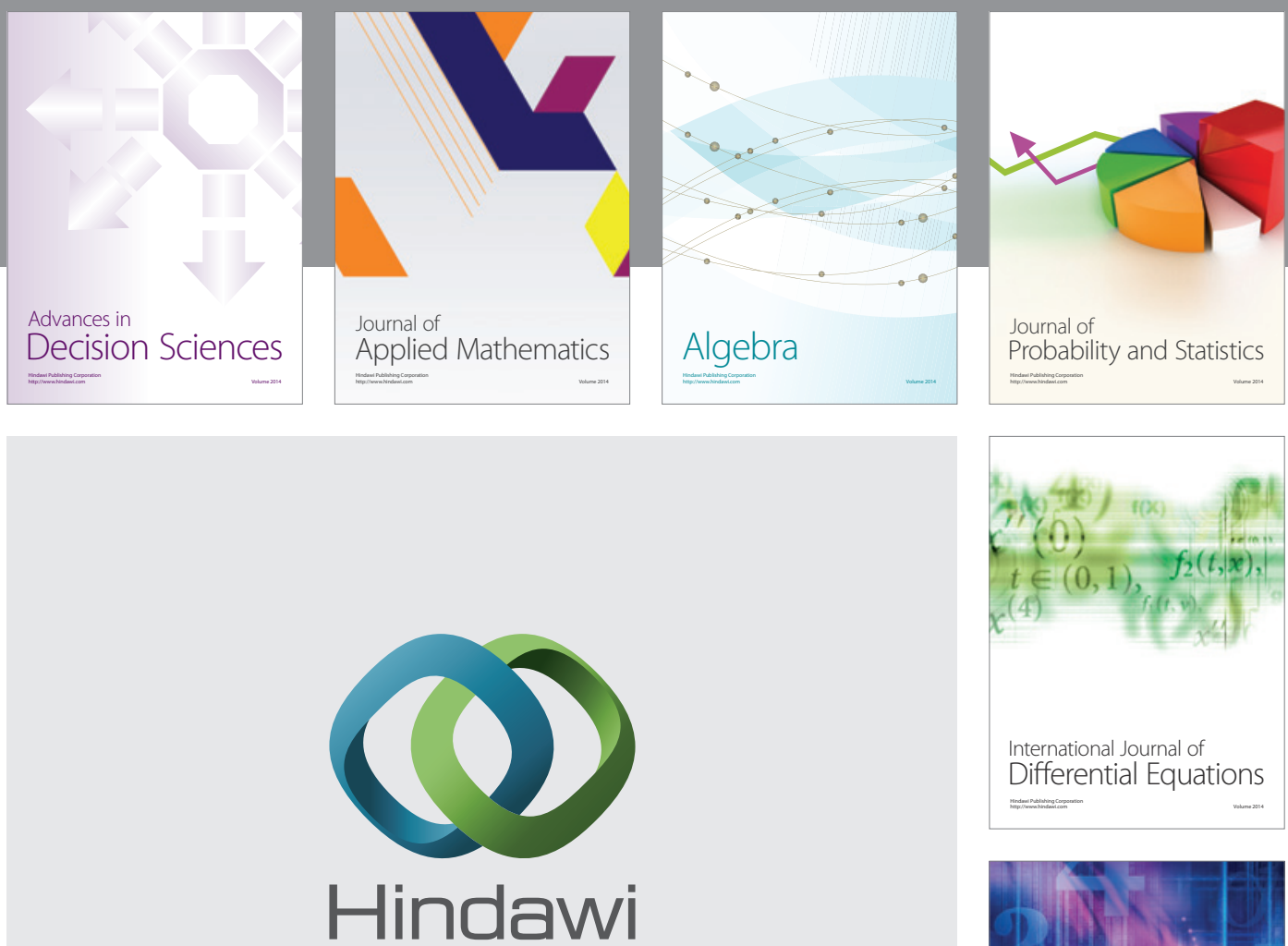

Submit your manuscripts at http://www.hindawi.com
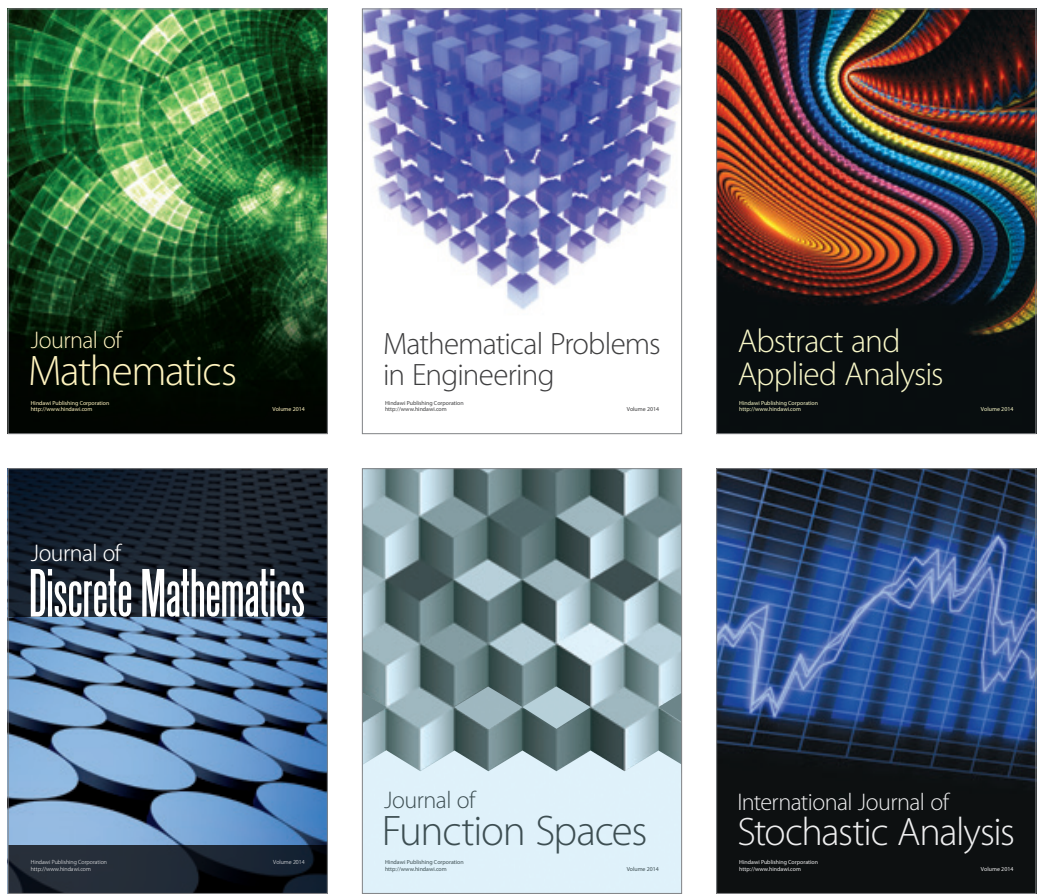

Journal of

Function Spaces

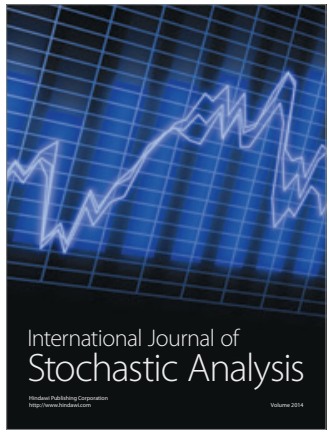

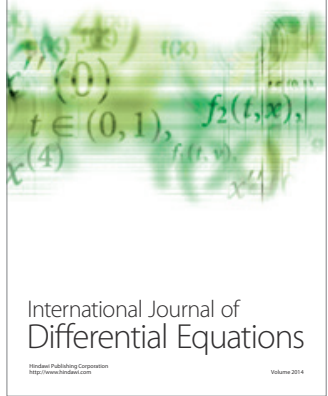
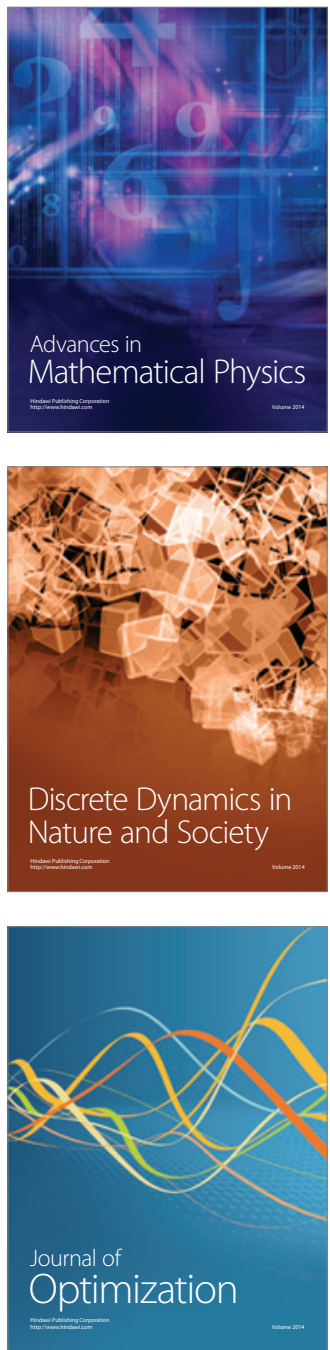